\title{
USING A THEORETICAL FRAMEWORK OF INSTITUTIONAL CULTURE TO ANALYSE AN INSTITUTIONAL STRATEGY DOCUMENT
}

\author{
Anthea Hydi Maxine Jacobs \\ Stellenbosch University \\ Email: jacobsa@sun.ac.za
}

\section{ABSTRACT}

This paper builds on a conceptual analysis of institutional culture in higher education. A theoretical framework was proposed to analyse institutional documents of two higher education institutions in the Western Cape, for the period 2002 to 2012 (Jacobs 2012). The elements of this theoretical framework are 'shared values and beliefs', 'language', 'symbols' and 'knowledge production'. Even though the larger study focused on two higher education institutions, the focus in this paper is only on Stellenbosch University (SU). The aim of the paper is to explore how the constitutive elements of the proposed theoretical framework are constructed in the Institutional Intent and Strategy 2013-2018 document of SU. The findings of the larger 2012 study suggested a missing link between transformation and institutional culture. Although SU is striving towards an inclusive campus or institutional culture, the contention is that transformation extends far deeper. The current analysis reveals that the challenges SU is facing are two-fold. Firstly, the university has to make sure that the proposed 'core processes' represent significant actions to address the challenges related to transforming the university's institutional culture. Secondly, SU should guard against the use of concepts such as 'redesign' to imply transformation.

Keywords: Constitutive meaning; higher education; institutional culture; theoretical framework; transformation

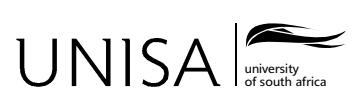

Education as Change

Volume 20 | Number 2 | 2016 | pp. 204-220

www.educationaschange.co.za

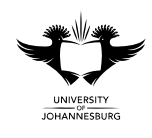

DOI: http://dx.doi.org/10.17159/1947-9417/2016/944 Print ISSN 1682-3206 | Online 1947-9417

(C) 2016 The Author(s) 


\section{INTRODUCTION}

This paper builds on a recently completed research project. This research was a conceptual analysis of 'institutional culture' in higher education, with the aim of developing an understanding of the concept, and more specifically, to explore how institutional culture is organised, constructed and articulated in the institutional documents of two higher education institutions in the Western Cape. The purpose of this paper is to use the theoretical framework of institutional culture which was constructed in the larger study (Jacobs 2012) to analyse the SU Institutional Intent and Strategy 2013-2018 document. Even though the larger study focused on two universities in the Western Cape, this paper draws only on the research related to SU.

According to a statement from the SU Institutional Intent and Strategy 20132018:

One of the important key focuses of transformation at Stellenbosch University is conceptualised as a combination of intentional changes in the institutional culture. (2013a, 10)

The following questions arise after reading this statement: (1) Does this statement represent mere compliance with the recommendation of the Higher Education Quality Committee (HEQC) (CHE 2007, 14), namely that SU develop a comprehensive strategy to transform its institutional culture? or (2) Do the intentional changes referred to represent concrete action plans or strategies to transform the SU institutional culture, which was one of the concerns identified in the larger conceptual analytic study of institutional culture (Jacobs 2012)?

Since the recommendation of the HEQC, there has been renewed debate about institutional culture on the campus of SU. An example of such debate was a conference entitled 'The Doors of Learning and Culture shall be Opened - Perspectives on Institutional Culture', held on the campus of SU in May 2008 (Botman 2008). Interestingly, the phrase 'The Doors of Learning and Culture shall be Opened' was taken from the Freedom Charter, which is a unique document in that, for the first time ever, people of South Africa were actively involved in formulating their own vision of an alternative South African society, one in which exploitation and oppression would be things of the past (ANC 2011). This conference was the brainchild of the late Rector and Vice-Chancellor of SU, Professor Russel Botman, and was intended to establish a series of 'courageous' conversations as a way of initiating a process for meaningful change to the institutional culture. In his opening address, Professor Botman stated that there was a very pertinent and pressing need for change in the institutional culture of universities, because the universities of today were vastly different from those that existed fifteen years ago. They are different in the way they pursue their core functions; they differ in terms of the composition of their students and staff; and they have become different places where people with divergent backgrounds, cultures and worldviews come together to study and work, 
and to generate knowledge for the common good. In a nutshell, difference is the common feature of institutions of higher learning today. The challenge for higher education institutions lies in how they cope with these differences and, one might add, how they deal with institutional cultures. Another example of a renewed focus on the topic of institutional culture was its prominent position on the agenda of SU's HOPE Project, which is an attempt by the university to create sustainable solutions to some of South Africa's and Africa's most pressing challenges (Botman 2010a). Both these examples indicate that SU is heeding the call of the HEQC (CHE 2007) to change its institutional culture. However, is the latter observation evident in the SU Institutional Intent and Strategy 2013-2018?

Having framed the purpose of this paper, I shall now briefly discuss the South African higher education policy context.

\section{SOUTH AFRICAN HIGHER EDUCATION POLICY CONTEXT}

The analyses of institutional documents in the larger study were preceded by a brief account of the South African higher education policy context (Jacobs 2012, 120), to which I now refer. As South Africa entered a process of social, economic and political reconstruction post-1994, it was evident that a thorough transformation of higher education was necessary in order to meet the national development needs of the country, as well as the requirements for participation in the global economy. This culminated in the release of several higher education policy documents, ranging from the National Policy Investigation (NEPI) of 1993, the Education White Paper 3: A Programme for the Transformation of Higher Education of 1997, the National Plan for Higher Education (NPHE) of 2001, through to the White Paper for PostSchool Education and Training of 2013. Since it is beyond the scope of this paper to detail all the policies pertaining to higher education, I mention only these few, which continue to guide and influence higher education.

The study of higher education policy development in South Africa leads me to two important observations (Jacobs 2012, 157-158). Firstly, the concept of transformation features prominently in initial higher education policy documents. However, following the introduction of the NPHE, there seems to be less emphasis in subsequent higher education policy documents on the concept of transformation. This may indicate a preoccupation with producing the skilled professionals and intellectuals required to sustain social and economic development in the context of globalisation. It may also be related to Muller et al.'s explanation of this as 'veer(ing) off track' $(2004,289)$. The authors offer two categories of explanation. The first category involves political motives. Government initially acted in good faith, but has since lapsed into bad faith - the so-called policy 'slippage' argument. Also, it can be argued that government never intended to implement the policy in the first 
place - the so-called 'symbolic' policy argument. The second category involves a technical explanation that attributes the change of course to implementation or capacity deficits at either a national or institutional level. These categories relate to the Soudien Report's explanation for the disjunction between policy and practice (Ministerial Committee on Higher Education Transformation 2008, 14). The report states that this appears to be the result of poor dissemination of information pertaining to policy, limited awareness of policies, a lack of awareness of roles and responsibilities pertaining to the implementation that flows from the policies, as well as a lack of institutional will $(2008,54)$.

Secondly, higher education has undergone major restructuring in recent years, the institutional effects of which are still being dealt with. New organisational arrangements, quality assurance procedures, financing processes and new relationships between the state and higher education institutions have called for new responses and adjustments by the key stakeholders, which affect the institutional culture of universities (Organisation for Economic Co-Operation and Development 2008, 374).

It is against the contextual background outlined above that I next explain the research methodology for the study.

\section{RESEARCH METHODOLOGY}

Drawing on the work of Harvey (1990), research methodology may be described as the 'interface between methodical practice, substantive theory and epistemological underpinnings'. Methodology is thus 'the point at which method, theory and epistemology' come together in the process of directly investigating specific instances within the social world. In the process of grounding empirical enquiry, methodology thus reveals the presuppositions that inform the knowledge that is generated by the inquiry (Harvey 1990, 1-2). I regard methodology as a broad theoretical framework or paradigm of study.

Critical hermeneutics was employed as a research methodology in the larger study to construct constitutive meanings of 'institutional culture'. What is critical hermeneutics? Critical hermeneutics draws on both hermeneutics and critical theory. A simple definition of hermeneutics is textual interpretation or, put differently, finding meaning in the hidden word (Byrne 2001, 1). I regard it as a suitable methodology for exposing the hidden meanings of institutional culture in institutional texts. Critical theory, on the other hand, is an emancipatory approach that enables us to dig beneath the surface of social life and uncover the assumptions that keep us from fully understanding how the world works (Marcuse, in Waghid 2004). Critical hermeneutics thus holds that the meaning we note on the surface makes up the mere periphery of much deeper layers of meaning. It provides a methodology for rigorous interpretation of institutional or university texts related to institutional culture, taking 
into consideration the historical backgrounds of institutions. In doing so, it seeks for meaning beyond the text, arousing a critical consciousness of institutional culture.

The constitutive meanings of 'institutional culture', constructed via the research methodology of critical hermeneutics, provided a theoretical framework for analysing the institutional policy documents of two universities in the Western Cape (in the larger study), for the period 2002 to 2010. Being led by an interest to determine whether there had been any progression in terms of transformation in the institutional culture since this study, I used the same theoretical framework to analyse the SU Institutional Intent and Strategy 2013-2018.

\section{THEORETICAL FRAMEWORK}

At this point I pause to unpack briefly the theoretical framework referred to. The question arises: What is a theoretical framework? Since it is difficult to work with a large set of constitutive meanings, and since no researcher can investigate a problem from all perspectives simultaneously, a theoretical framework becomes useful. It establishes a vantage point, a perspective or a set of lenses through which to view the research problem. As such, it can be regarded as a clarifying step in the research process. It sharpens the focus and consequently increases the clarity brought to the research problem (Cline 2011).

The theoretical framework in the larger study was constructed using the constitutive meanings of institutional culture as illuminated by a literature review (Jacobs 2012, 90). From a list of several constitutive meanings of institutional culture, four of the most frequently recurring meanings were used to construct a theoretical framework. The reason for this narrowing down is that it is difficult to work with a large number of constitutive meanings. Harvey $(1990,29)$ notes that while there may be a large list of concepts in practice, it is not necessary to attempt a separate critical analysis of each. They are interrelated, and so the key is to locate a central concept and critically analyse that. From that, the other concepts can be derived or reconstructed. Following Harvey, I narrowed a list of twelve meanings down to four main constitutive meanings. These four constitutive meanings are: (1) shared values and beliefs, (2) a shared language, (3) a shared set of symbols, and (4) the production of knowledge. These form the core of my theoretical framework and were used to analyse institutional documents. This means that the theoretical framework guided the research in terms of explaining how institutional culture is organised, constructed and articulated in institutional documents.

The following SU institutional documents were analysed in the larger study: Strategic Framework and Vision 2012; Self-Evaluation Report; Institutional Plan for the Planning Phase 2004-2006; Enrolment Plans; Employment Equity and Diversity Framework; HEQC Audit Report; Quality Development Plan; The Soudien Report: SU Submission, Findings and SU Response; Overarching Strategic Plan; and the HOPE Project and Vision 2015. These institutional documents cover the period 2002 
to 2010. The SU Institutional Intent and Strategy 2013-2018 followed afterwards, in 2013. It would therefore be interesting to see whether my current analysis reveals any changes since the research in 2012 .

In the interest of providing some background to the findings of the larger study (Jacobs 2012): it was found that all the constitutive meanings of the theoretical framework were addressed in the institutional documents of SU, which means that the institutional documents conformed to the theoretical framework. It was also found that SU had an excellent and comprehensive base of well-prepared and well-compiled institutional documents. However, most of these documents seemed to relate to quality and compliance with national policy requirements, with no significant actions or strategies to address the challenges related to transforming the university's institutional culture. The larger study indicated that although SU had introduced commendable strategic initiatives to transform its institutional culture, there had been insufficient engagement with the challenges of transformation.

The lack of an adequate articulation of the concept 'institutional culture' was of some concern, although the institutional documents analysed (Jacobs 2012) mostly conformed to the constitutive meanings of the theoretical framework. If there was no articulation, it followed that there would be an inadequate understanding of the concept. A deeper understanding was crucial if the important link between transformation and 'institutional culture' was to be realised. The argument was that there was a disjunction between 'institutional culture' and transformation policies (Jacobs 2012). One of the reasons for this disjunction was an impoverished understanding among higher education policy practitioners of the concept 'institutional culture', which created an impression of compliance with national policy requirements.

Before analysing the SU Institutional Intent and Strategy 2013-2018, I briefly discuss the nature of institutional documents. This will be followed by a historical background of SU.

Education White Paper 3 (DoE 1997) gives an idea of what an institutional plan is. The National Plan for Higher Education (NPHE) (Ministry of Education 2001) provides the framework for the development of institutional plans, which will in turn be influenced by particular institutional concerns and proposals. Institutional plans are expected to include the mission of the institution, proposed programmes, enrolment targets, race and gender equity goals, proposed measures to develop new programmes and human resource development plans (Ministry of Education 2001, section 1.4). They should also include plans for academic development, research development and infrastructural development. Institutional plans can therefore be regarded as showing the direct impact of government policies on an institution. They are what Soltis $(1988,196-203)$ refers to as the public dimension of education and, as such, are open to philosophical analysis. Evers $(1998,120)$ expresses himself in favour of philosophers of education making pronouncements on a range of substantive educational issues, including educational policy. This provides justification for my 
analyses of institutional plans. Institutional planning at SU was done according to the proposed format of the NPHE.

\section{HISTORICAL BACKGROUND OF STELLENBOSCH UNIVERSITY}

For hermeneutic research, as in the case of the conceptual analytic larger study (Jacobs 2012), history serves as an important part of context. It is therefore important to develop a thorough familiarity with the historical aspects of SU in order to understand texts related to its institutional culture.

Stellenbosch is South Africa's oldest town. It was founded in 1679 by the then Governor of the Cape Colony, Simon van der Stel, who named the town after himself. Stellenbosch means literally '(van der) Stel's forest'. The town lies near the head of the Eerste River Valley and is one of the most beautiful towns in South Africa. The valley produces grapes for some of the world's finest wines. Stellenbosch is at the heart of a fertile farming area, where many wine farms are found. This charming little town has a sheltered location, flanked by the Stellenbosch and Jonkershoek Mountains (Explore South Africa 2010). These geographical observations are important in the context of this research because a university's physical setting (its external environment) can be a potent symbol, suggesting a proud tradition (ASHE 2005).

From very early on, Stellenbosch had a significant involvement with the history of education in South Africa. Regular school instruction began as early as 1685 . By the 1840 s, the Cape Colony was operating a system of centrally controlled public schools. Under this system, Stellenbosch was recognised as a divisional centre for education. In 1886, under the new Education Act, the local public school was reorganised as a First Class Public School, also known as the Stellenbosch Gymnasium. As time went on there was an increase in the demand for more advanced teaching. Stellenbosch Gymnasium set up its own professorial division in 1874 under the Higher Education Act to help meet this new demand, which led to the Arts Department, the germ of the present Faculty of Arts. In 1881, the Arts Department received its charter as a college, and the status and constitution of the Stellenbosch College were conferred by a Special Act of Parliament. In 1887, the jubilee year of Queen Victoria's reign, the queen agreed that the college could be named the Victoria College of Stellenbosch. Many years later, in 1916, the Union Parliament passed the University Act. As a result, the Victoria College of Stellenbosch became an independent university (SU 2011).

This background illustrates that $\mathrm{SU}$ is one of the oldest universities in South Africa. It is regarded as a traditional university, meaning that it offers bachelor degrees and has a strong research capacity and high proportion of postgraduate students (IEASA 2012, 14). Today, SU is regarded as one of the top researchintensive institutions on the African continent (SU 2010a). In 2008, SU's formal 
weighted research output per academic staff member was 2.13 , the highest research output per capita of any university in the country. In addition, the university's research teams produce about $12 \%$ of the research output in South Africa. SU has 270 researchers with ratings from the National Research Foundation (NRF) (CHEC 2010, 5). A 2010 report by the Centre for Higher Education Transformation (CHET) identified three different university clusters (red, green and blue) in South Africa, grouped according to function. SU falls in the red cluster, which represents the top research-intensive universities (SU 2010b). The HEQC, in its Audit Report (CHE 2007, 41), describes SU as a medium-sized Afrikaans university located in one of the richest agricultural areas in the country. According to the 2013 annual official census data, a total of 28156 students were enrolled at SU (SU 2013c). The history of SU has been strongly associated with the development of apartheid, and until the late 1980s the institution was characterised as being racially and ethnically exclusive. In fact, when I arrived on the campus of SU as a first-year student in 1987, I was one of only a handful of non-white students. My admission to the university was subject to a photograph accompanying my initial application. Six years later, on 27 April 1994, the Afrikaner political power hegemony ended with the country's first democratic elections. This paved the way for the introduction of several documents expressing broad sentiments in favour of transformation.

Before examining the SU Institutional Intent and Strategy 2013-2018, using the theoretical framework (Jacobs 2012), I present a brief introduction to the document.

\section{INSTITUTIONAL INTENT AND STRATEGY 2013-2018}

The SU Institutional Intent and Strategy 2013-2018 (SU 2013a) was formulated during the leadership of the late Professor Russel Botman. I mention this because there is a significant relationship between leadership and institutional culture in higher education. This has been demonstrated by scholars like Tierney and Schein. Tierney (1988) identified leadership as one of six important elements for analysing organisational or institutional culture. Tierney's elements are related to Schein's (1993) account of the importance of management or leadership in understanding institutional culture.

Professor Botman became Rector and Vice-Chancellor of SU in 2006. One of his main tasks was to guide SU towards achieving the goals of Vision 2012. According to Vision 2012 (SU 2003), the university:

- is an academic institution of excellence and a respected knowledge partner;

- contributes towards building the scientific, technological, and intellectual capacity of Africa;

- is an active role-player in the development of the South African society;

- has a campus culture that welcomes a diversity of people and ideas; 
- promotes Afrikaans as a language of teaching and science in a multilingual context.

Botman introduced a new pedagogical framework, a 'Pedagogy of Hope' (Botman 2010b), to address the contradiction posed by the contrast between the university's apartheid past and a future in which the university wished to position itself as an institution of excellence. On the one hand, this called for SU to build on the high standards it had achieved as a world-class research university. On the other hand, this required the institution to change and to build an institutional culture to embrace the challenges of the 21 st century, including challenges posed by new generations of young people, new ways of learning, new opportunities for research and the need to harness emerging technologies.

Like other universities in South Africa, and like universities worldwide, SU finds itself in a new and rapidly changing 'playing field'. This emerges from worldwide trends such as the information and knowledge revolution, increasing internationalisation and the continuous need for new and applied knowledge. The SU Institutional Intent and Strategy 2013-2018 recognises these rapid changes. It states that the university's strategic positioning for the 21 st century is anchored in creating and sustaining an environment of inclusivity, transformation, innovation, diversity, and maintaining excellence with a focus on the future. This anchorage is organised around four strategic areas: broadening the university's knowledge base, promoting student success, increasing diversity and becoming systematically more sustainable (SU 2013a, 4).

I shall now examine the SU Institutional Intent and Strategy 2013-2018 by using the theoretical framework (Jacobs 2012) to determine how institutional culture is organised, constructed and articulated in the document.

\section{DISCUSSION OF FINDINGS}

My analysis of the SU Institutional Intent and Strategy 2013-2018 document demonstrates several complexities with regard to institutional culture. In this section I discuss my main findings in terms of the constitutive elements of the theoretical framework.

Shared values and beliefs. The SU Institutional Intent and Strategy 20132018 is built on the following values: excellence in everything the university does, shared accountability (all stakeholders are jointly responsible for achieving the university's vision), empathy (promoting human dignity), innovation (thinking and acting in new and different ways), and leadership in service of others (leading with humility, responsibility and understanding) (SU 2013a, 8). The significance of these value statements is two-fold. Firstly, these values lay a solid foundation for SU's future development. It also enables the university to become a more representative university, with a greater measure of equal empowerment and human dignity for all. 
At the same time, the university is keeping pace with the knowledge economy of the 21 st century. Secondly, these value statements provide evidence that the constitutive meaning of 'shared beliefs and values' in Jacobs's theoretical framework features in the SU Institutional Intent and Strategy 2013-2018 document. The current analysis shows a shift from building an institutional culture that promotes the values enshrined in the Constitution (characteristic of previous institutional documents), towards a focus on excellence, innovation and leadership. This shift is in line with Greenwald's observation (2010) that an emphasis on training university students for leadership is occurring in part because of the perception that countries worldwide are increasingly suffering crises of leadership. Greenwald continues to argue, and I concur, that 'today's students are graduating into a world that is much riskier' than before. There is a realisation that economic crises go much deeper than a drop in the stock market. Students find themselves in a 'micropreneurial age' (Greenwald 2010). They will have 'multiple jobs and even multiple careers' during their lifetime. In short, students need to be equipped to make their own opportunities. They need to be taught the appropriate leadership skills, knowledge and qualities befitting $21 \mathrm{st}$ century students.

Language. One of the strategic goals of the SU Institutional Intent and Strategy 2013-2018 is to increase access at SU where students can, as far as practically feasible, learn in their language of choice (Afrikaans or English) (SU 2013a, 16). The aspect of language seems to have had a great impact on SU's institutional culture (Jacobs 2012, 255). Language features prominently in most institutional documents since 2002 and remains a contentious subject. I contend that despite SU's best intentions with its language policy, it seems the fact that Afrikaans is the language of preference at undergraduate level plays a major role in making staff and students who do not speak Afrikaans as a first language feel unwelcome. To illustrate this, I refer to two examples. Firstly, a survey conducted in 2006 of the experiences of students, lecturers and administrative staff of the implementation of the SU language policy and plan, found that African ('black') students felt marginalised (SU 2006). Secondly, at the May 2008 conference entitled 'The Doors of Learning and Culture shall be Opened - Perspectives on Institutional Culture' that was held on the campus, a black student reported that some of his fellow black students felt excluded because of the widespread use of Afrikaans on campus (Botman 2008). Other students considered leaving the university because of the challenges of having to attend lectures in Afrikaans (Mvulani, in Pieterse 2008, 48). In the context of the history of SU and its association with the development of apartheid (CHE 2007, 41), as well as its reputation (until the late 1980s) of being racially and ethnically exclusive, this feeling of alienation is not surprising (Jacobs 2012, 255). Moreover, it would seem that the language policy of SU is perpetuating the exclusion of certain groups of students. If SU intends to prepare its students for participation in the global economy, it has to pursue the goal of an inclusive institutional culture and ensure 
that non-Afrikaans speakers feel welcome. Despite tensions between the use of Afrikaans on the one hand, and the demands of broadening diversity and the pursuit of excellence on the other, language remains a constant source of debate.

The current analysis shows a reaffirmation of SU's commitment to multilingualism, where Afrikaans is used and developed as an academic language, while utilising the value of English as an international academic language. Attention is also paid to the advancement of isiXhosa. These initiatives indicate a positive move in the direction of inclusivity in terms of language. Phrases such as 'students can, as far as practically feasible, learn in their language of choice (Afrikaans or English)' (SU 2013a, 16) are encouraging, as are the following phrases from the 'Language as an instrument of empowerment at Stellenbosch University' project booklet: 'no development or empowerment without language development and language empowerment' (project motto); and 'without proper language support, a language policy is worth nothing' (SU 2014).

Symbols. This constitutive meaning of the theoretical framework for policy analysis does not feature prominently in the SU Institutional Intent and Strategy 20132018. However, reference is made to 'Our Difference' and 'Value Proposition' (SU 2013a, 3) which, in my opinion, is presented in a slogan-like fashion. This reminds one of the fact that symbols can serve as recognition, or reminder, or both (Eikenberry, in Bizshifts-Trends 2012). In this case, the difference and value propositions were adopted as a reminder of the intention of the university to remain committed to creating a culture of inclusivity and diversity of experiences, as well as educating tomorrow's leaders. The usefulness of the difference and value propositions lies in its power to frame the institution's intentions to develop an inclusive institutional culture and to provide excellent quality education.

As in the case of the larger study (Jacobs 2012), the current analysis finds a similar lack of pertinent reference to the value of symbols. The question arises: Why does SU continue its reluctance to recognise the part that symbols could play in articulating a transformative institutional culture? Does this relate to the institutional culture at SU being a classic case of a deeply embedded university culture that developed over centuries and from which it is difficult to move away (see Mora 2001, 95)? Mora refers to 'unspoken common assumptions'. Making sense of or becoming aware of such 'unspoken common assumptions' is not easy and this could explain why SU, in its efforts to transform, has largely ignored the part that symbols could play in articulating a transformative institutional culture. The latter view is also held by Van Wyk $(2009,338)$. It is encouraging that the Task Team on a Welcoming Institutional Culture at SU, in its advisory document to the Rector (SU 2013b, 7), suggests that the university engages in an introspective focus on the usefulness of the rituals and symbols of the university.

Knowledge production. In terms of research and knowledge production, the SU Institutional Intent and Strategy 2013-2018 shows that SU wants to host and train the thought leaders of the future: 'Stellenbosch University... a place of discovery and 
excellence where both staff and students are thought leaders in advancing knowledge in the service of all stakeholders' (SU 2013a, 7). SU also strives to be innovative and creative in solving the problems and challenges facing the world through researchrelated activities. The university wants to implement appropriate and sustainable approaches to the development in Africa and aims to improve the lives of people in its community, the country and on the continent. The way the university wants to achieve this is through the institutional focus of broadening its knowledge base by an increased access to knowledge markets (SU 2013a, 6).

The focus on producing new knowledge in order to make a difference in the living conditions of people, emphasised in previous institutional documents, is carried through to the SU Institutional Intent and Strategy 2013-2018. The current analysis reveals the added dimension of broadening the university's knowledge base through increasing access to new knowledge markets. Two ideas remain: (1) The idea of laying a foundation for a future filled with hope, and (2) the concept of hope becoming a concept with the potential of assisting the process of transformation. These ideas have an impact on the institutional culture of SU and have helped to focus efforts for the production of new knowledge, as well as on the importance of access to new, diverse knowledge markets.

The SU Institutional Intent and Strategy 2013-2018 lays the foundation for the university's positioning as an institution able to meet the demands of higher education in the 21 st century. In fact, it serves as a virtual compass, indicating how SU plans to move forward and establish itself as an excellent university of international stature. In addition, the SU Institutional Intent and Strategy 2013- 2018 puts emphasis on the development of leadership skills. The reason for this is that the strategy takes into account the objectives of South Africa's National Development Plan (NDP) that aims to eliminate poverty and reduce inequality by 2030 . The NDP states that South Africa can realise these goals by drawing on the energies of its people, growing an inclusive economy, building capabilities, enhancing the capacity of the state, and promoting leadership and partnerships throughout society (National Planning Commission 2011, 14). In this way, the SU Institutional Intent and Strategy 2013-2018 is aligned with the NDP.

\section{USEFULNESS OF STUDY FOR HIGHER EDUCATION POLICY DEVELOPMENT}

In explaining the usefulness of this analysis of institutional culture for higher education policy development in general, as well as for institutional policy development in particular, I use McLaughlin's $(2000,449)$ explanation of the different aspects of the policy-making process. McLaughlin distinguishes between 'analysis of policy' and 'analysis for policy'. 
Even though I mostly relied on 'analysis of policy', my study is useful in terms of 'analysis for policy'. 'Analysis for policy', according to McLaughlin (2000, 449), contributes to the formulation of policy in two ways. Firstly, it involves policy advocacy, which entails making specific policy recommendations. The larger study has led to several policy considerations or recommendations. For example, I found that the institutional documents of SU relate strongly to knowledge production. I pointed out the implications of an increasing emphasis on knowledge production for university leaders and institutional policy developers. In the current analysis I show, amongst other things, how the strong emphasis on producing leadership skills in the SU Institutional Intent and Strategy 2013-2018 can be traced to the objectives of the NDP and provides an important insight for role players concerning institutional policy development. Secondly, 'analysis for policy' provides information for policy development through supplying data which could, for example, assist with conceptual clarification. Both the larger and current studies have assisted in clarifying the understudied concept of institutional culture in the context of higher education, by breaking it down into its constituent parts. These two explanations qualify why this study can be regarded as 'analysis for policy'.

\section{CONCLUSION}

The aim of this paper was to explore how the constitutive elements of the proposed theoretical framework of institutional culture are constructed in the Institutional Intent and Strategy 2013-2018 document of SU. An analysis of this document shows evidence that SU displays an increased visionary awareness of the university becoming an inclusive, innovative and future-focused institution in the 21 st century. This awareness has been heightened by the recent passing of the Rector and ViceChancellor of SU, Professor Russel Botman. Professor Botman's message of hope, which he wanted to see embedded in everything the university stands for, is arguably one of his most important legacies. Part of this concept of hope is that the university fully recognises and embraces diversity so as to collectively tackle the challenge of a constantly changing world.

The SU Institutional Intent and Strategy 2013-2018 emphasises the university's commitment to excellence, innovation and leadership ('shared values and beliefs'), places the focus on the university's multilingual approach ('language'), presents difference and value propositions as symbolic in framing the university's intentions to develop an inclusive institutional culture ('symbols'), and refers to producing new knowledge in order to make a difference in the living conditions of people ('knowledge production'). Against this background the SU Institutional Intent and Strategy 2013-2018 relates, to varying degrees, to all the constitutive meanings of the theoretical framework. Perhaps this is because the Institutional Strategy document was developed during a time when the university policy was subject to alignment to the NDP, which focuses on, amongst others, promoting leadership '(shared 
values and beliefs'), inclusivity ('symbols' and 'language') and building capabilities ('knowledge production') (National Planning Commission 2011).

The concept 'institutional culture' is prominently mentioned in the Institutional Intent and Strategy 2013-2018, which seems to indicate that the missing link between transformation and institutional culture identified by Jacobs (2012) in the larger study has narrowed, but is still there. I still get the sense that 'transformation' is equalled to the 'redesign of core processes' (SU 2013a, 5), which is perhaps cause for concern. This observation aside, SU is indeed, through its Transformation Plan (SU 2013b, 6) striving towards an inclusive campus or institutional culture, continuing its initiatives to transform its student profile and to establish a more diverse staff complement. Even though it is encouraging that SU regards the promotion of diversity as an important aspect of transformation, I contend that transformation extends far deeper. I concur with Badat (2013) who argues that transformation in higher education involves much more than changing the demographics of a campus community. Speaking at the ViceChancellor's Mwalimu Julius Nyerere $10^{\text {th }}$ Annual Lecture on Lifelong Learning at the University of the Western Cape (UWC), Badat said that transformation is about 'creating institutional cultures that genuinely respect and appreciate difference and diversity'. Against the background of this argument by Badat, I am even more encouraged by a phrase from a recent opinion article by George Steyn, Chairperson of the SU Council, regarding the SU vision for transformation. According to Steyn (2014), 'transformation relates to much more than staff and student statistics'. It includes, amongst others, fostering a welcoming campus culture for different people.

However, a few challenges remain. Firstly, the university needs to ensure that the 'core processes' represent significant actions or strategies to address the challenges of transforming the university's institutional culture. Secondly, SU should heed Chisholm's argument $(2004,12)$ that the use of certain terms (such as 'redesign') to imply transformation tends to deplete them of specific significance. These are important considerations for institutional policy development.

\section{REFERENCES}

ANC (African National Congress). 2011. The Freedom Charter. Retrieved from: http://www.anc. org.za/ (accessed 16 July 2012).

ASHE (Association for the Study of Higher Education). 2005. Institutional culture in substance and form. ASHE Higher Education Report 31(2): 55-74.

Badat, S. 2013. Higher education, transformation and lifelong learning. Paper presented at the Vice-Chancellor's Mwalimu Julius Nyerere 10th Annual Lecture on Lifelong Learning, University of the Western Cape, 14 October 2013. Retrieved from: http://www.uwc.ac.za/ Students/DLL/Pages/Archives.aspx (accessed 21 August 2014).

Bizshifts-Trends. 2012. Power of symbols, symbolisms, and brand in developing global markets: Anthropology of business, marketing, leadership. Retrieved from: http://bizshifts-trends. 
com/2012/01/23/power-of-symbols-symbolisms-and-brand-in-developing-global-marketsanthropology-of-business-marketing-leadership/ (accessed 29 February 2012).

Botman, R. 2008. The doors of learning and culture shall be opened. Perspectives on changing institutional culture. Speech delivered at the conference on changing institutional culture, Stellenbosch University, 30 May 2008.

Botman, R. 2010a. Public launch of Stellenbosch University's HOPE project. Speech prepared for the launch of Stellenbosch University's HOPE project, Stellenbosch University, 21 July 2010. Retrieved from: http://www.sun.ac.za/english/Documents/Rector/speeches/HOPE_ Project.pdf (accessed 1 September 2011).

Botman, R. 2010b. A collegial discussion on the 'Pedagogy of Hope' at Stellenbosch University. Opening remarks prepared for discussion, Stellenbosch University, 1 June 2010. Retrieved from:http://www.sun.ac.za/english/Documents/Rector/speeches/PedagogyOfHope.pdf (accessed 1 September 2011).

Byrne, M. 2001. Hermeneutics as a methodology for textual analysis. AORN Journal 73(5): 968970.

CHE (Council on Higher Education). 2007. Audit report on Stellenbosch University. Pretoria: CHE.

CHEC (Cape Higher Education Consortium). 2010. Four universities. Unlimited possibilities. Wynberg: CHEC.

CHET (Centre for Higher Education Transformation). 2010. Centre for Higher Education Transformation Report.

Chisholm, L. 2004. Introduction. In Changing class: Education and social change in postapartheid South Africa. Edited by L. Chisholm. Pretoria: Human Science Research Council Press.

Cline, D. 2011. Logical structure, theoretical framework. Centre for Excellence in Education, Arkansas State University. Retrieved from: http://education.astate.edu/dcline/ (accessed 16 August 2011).

DoE (Department of Education). 1997. Education White Paper 3: A programme for the transformation of higher education. General Notice 1196 0f 1997. Pretoria: Department of Education.

Evers, C.W. 1998. Analytic and post-analytic philosophy of education: Methodological reflections. In Philosophy of education: Major themes in the analytic tradition. Volume I. Edited by P. Hirst and P. White, 120-132. London and New York: Routledge.

Explore South Africa. 2010. History of Stellenbosch. Retrieved from: http:/www. exploresouthafrica.net/westerncape/stellenbosch/history/index.htm/ (accessed 26 March 2012).

Greenwald, R. 2010. Today's students need leadership training like never before. The Chronicle of Higher Education. Retrieved from: http://findarticles.com/ p/articles/mi_m1TOT/is_2_10/ai_n25009752/(accessed 9 July 2014).

Harvey, L. 1990. Critical Social Research. London: Unwin Hyman.

IEASA (International Education Association of South Africa). 2012. Higher education in context - South African higher education: Facts and figures. Retrieved from: http://www.ieasa. studysa.org/resources/Study_SA/Facts_Figures_section.pdf/(accessed 13 July 2012). 
Jacobs, A.H.M. 2012. A critical-hermeneutical inquiry of institutional culture in higher education. Unpublished Doctor of Philosophy Dissertation. Stellenbosch: University of Stellenbosch.

McLaughlin, T.H. 2000. Philosophy and educational policy: Possibilities, tensions and tasks. Journal of Education Policy 15(4): 441-457.

Ministerial Committee on Higher Education Transformation. 2008. Report of the Ministerial Committee on Transformation and Social Cohesion and the Elimination of Discrimination in Public Higher Education Institutions: Final report. Pretoria.

Ministry of Education. 2001. National Plan for Higher Education. Pretoria: Government Printers.

Mora, J. 2001. Governance and management in the new university. Tertiary Education and Management 7: 95-110.

Muller, J., P. Maassen and N. Cloete. 2004. Modes of governance and the limits of policy. In Transformation in higher education: Global pressures and local realities in South Africa. Edited by N. Cloete, P. Maassen, R. Fehnel, T. Moja, H. Perold and T. Gibbon, 289-310. Dortrecht: Kluwer Academic Publishers.

National Planning Commission. 2011. National Development Plan. Retrieved from: http:// www.npconline.co.za/medialib/downloads/home/NPC\%20National\%20Development $\% 20$ Plan\%20Vision\%202030\%20-lo-res.pdf (accessed 1 July 2014).

OECD (Organisation for Economic Co-Operation and Development). 2008. Reviews of national policies for education South Africa. Retrieved from: http://www.oecd.org/southafrica/ (accessed 16 August 2014).

Pieterse, H.M. 2008. Democratic citizenship education and the university in a cosmopolitan world. Unpublished Master of Education Thesis. Stellenbosch University.

Schein, E. 1993. Defining organisational culture. In Classics of organisation theory. Edited by J. Shafritz and J.S. Ott, 369-376. Fort Worth: Harcourt College Publishers.

Soltis, J. 1988. Perspectives on philosophy of education. In Philosophy of education: Major themes in the analytic tradition. Volume I. Edited by P. Hirst and P. White, 196-204. London and New York: Routledge.

Stellenbosch University. 2003. Vision 2012.

Stellenbosch University. 2006. Survey of the experience of the implementation of the Stellenbosch University Language Policy and Plan (2006) - Executive summary. Retrieved from: http://www.sun.ac.za/university/taal/hersiening/docs/exec\%20summary \%20of\%20language \%20survey\%207\%20sept\%202006.pdf/ (accessed 1 April 2012).

Stellenbosch University. 2010a. HOPE Project. Retrieved from: http://www.thehope project.co.za/ (accessed 29 August 2011).

Stellenbosch University. 2010b. Baseline document of the Committee for Strategic Enrolment and Management 2010-2015.

Stellenbosch University. 2011. Some historical notes: A university in the making. Retrieved from: http://www.sun.ac.za/university/history/history.htm/ (accessed 11 June 2011).

Stellenbosch University. 2013a. Institutional Intent and Strategy 2013-2018. Retrieved from: http://www.sun.ac.za/english/management/rector/Documents/Institutional\%20Intent $\% 20$ and\%20Strategy\%202013-2018.pdf (accessed 14 April 2014).

Stellenbosch University. 2013b. Task team on a welcoming culture at Stellenbosch University: Advisory document to rector. Retrieved from: http://www.sun.ac.za 
/english/Documents/Rector/welcoming\%20culture\%20at\%20Stellenbosch\%20University. pdf (accessed 11 July 2014).

Stellenbosch University. 2013c. Statistical profile. Retrieved from: http://www.sun.ac.za/english/ Pages/statistical_profile.aspx (accessed 26 January 2015).

Stellenbosch University. 2014. A bearer of hope. Language as an instrument of empowerment at Stellenbosch University. Retrieved from: http://www.sun.ac.za/english/about-us/language (accessed 25 July 2014).

Steyn, G. 2014. Stellenbosch to stay on course. Weekend Argus, 24 August.

Tierney, W.G. 1988. Organisational culture in higher education. Defining the essentials. Journal of Higher Education 59(1): 1-21.

Van Wyk, B. 2004. An analysis of transformation at three South African universities. Education as Change 8(1): 164-186.

Van Wyk, B. 2009. Universities as organisations or institutions? The culture debate and one institution. In Higher education in South Africa. A scholarly look behind the scenes. Edited by E. Bitzer, 329-347. Stellenbosch: SUN Media.

Waghid, Y. 2004. BEd Hons philosophy of education study guide. Stellenbosch: SUN Media. 